\title{
Explorando as associações entre redes pessoais e acesso a bens materiais em duas metrópoles brasileiras
}

\author{
Eduardo Marques- Departamento de Ciência Política da USP e Centro de \\ Estudos da Metrópole (CEM)- Brasil \\ Graziela Castello \& Renata M. Bichir - Centro de Estudos da Metrópole
}

(CEM)- Brasil

\begin{abstract}
Resumo
Esse artigo discute redes pessoais de indivíduos em situação de pobreza em doze localidades em São Paulo e Salvador, Brasil. Resultados anteriores dessa mesma investigação estudaram as redes de 209 indivíduos em situação de pobreza e 30 de classe média em São Paulo. A pesquisa investigou o papel das redes sociais na reprodução da pobreza, levando em conta o acesso dos indivíduos a bens e serviços obtidos em mercados, mas também os alcançados via ajudas e troca sociais. $O$ presente artigo inclui os resultados de outras 152 redes de indivíduos que vivem em cinco localidades pobres de Salvador.

O artigo parte da discussão comparativa das características das redes nas duas cidades. Em geral, os resultados confirmam os anteriores, embora com peculiaridades importantes em relação ao papel do espaço e da segregação residencial. Em seguida, realizamos análise quantitativa das associações entre renda, acesso a empregos e empregos de melhor qualidade, testando a importância de atributos sociais considerados classicamente pela literatura, mas também de medidas das redes e das sociabilidades dos indivíduos. Os resultados confirmam a importância central dos tipos de redes e de sociabilidade na explicação das situações de pobreza urbana.
\end{abstract}

Palavras-chave: redes pessoais, pobreza, segregação residencial, São Paulo, Salvador.

\begin{abstract}
This article discusses personal networks of individuals in poverty who live in twelve localities in São Paulo and Salvador, Brazil. Previous results from this same investigation analyzed the networks of 209 poor individuals and 30 middle class individuals in São Paulo. The research explored the role of social networks in poverty reproduction, taking into account the access to goods and services obtained through markets, as well as those received from helps and social aids. The present article complements the information with 152 other networks of individuals in poverty who live in five locations in Salvador.

The article departs from the comparison of the characteristics of social networks in the two cities. In general, the results confirm previous findings, but important differences associated with the role of space and residential segregation arise. Following, we developed quantitative analyses of the associations between networks, income, employment and job tenure, testing the importance of social attributes usually considered by the literature, but also network and sociability measures. The results confirm the central importance of network and sociability types in the explaining of poverty conditions.
\end{abstract}

Key words: Personal networks, deprivation, residential segregation, São Paulo, Salvador. 
Redes sociais têm sido cada vez mais consideradas como elementos importantes na construção de uma grande variedade de processos, desde a mobilização política em movimentos sociais ou partidos políticos (Mische 2008, Hedstrom et al., 2000), até as ações e a estrutura de relações formais e informais entre as elites políticas e econômicas (Misruchi e Schwartz, 1987, Heinz et al. 1997, Kadushin, 1995) ou na estruturação de áreas de políticas públicas (Knoke et al., 1996), entre muitos outros temas. Outro número significativo de estudos têm examinado as redes pessoais - aquelas que cercam os indivíduos em particular. Essas análises visam estudar os efeitos da sociabilidade dos diversos grupos sociais para compreender como os laços sociais são construídos e transformados (Bidart e Lanevu, 2005; Degenne, 2009; Grosseti, 2009) e suas conseqüências para fenômenos como integração social, imigração e apoio social (Campbell e Lee, 1992; Jariego, 2002; Ferrand, 2002).

No caso específico da pobreza, a literatura tem estabelecido de forma cada mais eloquente como tais redes medeiam o acesso a recursos materiais e imateriais e, ao fazê-lo, contribuem de forma destacada para a reprodução das condições de privação e das desigualdades sociais. Portanto, analisar a diversidade de tais redes, assim como a sua mobilização cotidiana diferenciada entre indivíduos e em diferentes momentos, representa uma chave importante para melhor compreendermos os processos de reprodução da pobreza. A integração das redes ao estudo da pobreza pode permitir a construção de análises que escapem dos pólos analíticos da responsabilização individual dos pobres por sua pobreza (e seus atributos), assim como de análises sistêmicas que foquem apenas nos macroprocessos e constrangimentos estruturais que cercam o fenômeno. A literatura brasileira sobre o tema tem sido marcada por uma oposição entre enfoques centrados nesses dois campos, embora os últimos anos tenham assistido a uma clara hegemonia dos estudos baseados em atributos e ações individuais para a explicação da pobreza. Parece-nos evidente que tanto constrangimentos e processos supra-individuais (incluindo os econômicos) quanto estratégias e credenciais dos indivíduos importam para a constituição e a reprodução de situações de pobreza. Entretanto, essas devem ser analisadas no cotidiano dos indivíduos, de maneira a que compreendamos de que forma mediam o seu acesso a mercados, ao Estado e às trocas sociais que provêm bem-estar (Esping-Andersen, 2000).

Este artigo pretende contribuir para o debate discutindo as características das redes pessoais de indivíduos em situação de pobreza em doze locais, nas cidades de São Paulo e em Salvador, Bahia. O trabalho dá continuidade a pesquisa anterior que estudou as redes pessoais de 209 indivíduos em situação de pobreza e 30 
indivíduos de classe média, em sete locais em São Paulo (Marques, 2010). Este trabalho acrescenta às evidências anteriores os resultados de 153 redes pessoais de indivíduos em situação de pobreza que vivem em cinco locais diferentes na cidade de Salvador. A escolha das duas cidades visou cobrir situações muito diferentes em termos urbanos, do mercado de trabalho, da estrutura social e dos padrões de pobreza.

Inicialmente, o artigo discute comparativamente as características das redes pessoais dos indivíduos em São Paulo e Salvador. Em geral, os resultados confirmam descobertas prévias sobre a diversidade e a importância das redes nas condições de vida dos mais pobres. Em seguida, o artigo investiga o impacto das redes pessoais e de outros atributos sobre indicadores considerados usualmente como definidores de situações de pobreza - a obtenção de trabalho, de trabalho com algum grau de proteção, a presença de situações de vulnerabilidade social (medida de forma composta considerando estrutura familiar, renda, trabalho e habitação) e o montante de rendimentos das pessoas em situação de pobreza. Em todos esses casos estão em jogo dimensões que influenciam fortemente o acesso dos indivíduos à obtenção de bens e serviços no mercado de forma a mitigar suas condições de pobreza. Essa não é a única forma de acesso a tais bens e serviços, mas o acesso mediado por ajuda social não é explorado neste artigo. ${ }^{1}$

A estrutura do artigo segue as etapas da construção desse exercício analítico. A próxima seção situa teoricamente o estudo, assim como especifica as principais ferramentas de pesquisa utilizadas. A segunda seção apresenta as características básicas das redes e a terceira seção testa os condicionantes do emprego, do emprego protegido, da precariedade social e dos rendimentos. Ao final, retornamos os principais achados.

\section{Conectando conceitualmente redes e pobreza}

Em termos teóricos, definimos pobreza como o conjunto heterogêneo de situações associadas a privações de bem-estar sendo, portanto, nitidamente multidimensional. Nesse sentido, envolve um conjunto amplo de dimensões econômicas, mas também sociais, em sentido amplo (incluindo aí práticas, padrões de sociabilidade, referenciais culturais que dão sentido à própria condição, etc), assim como políticas (visto que se vinculam às opções de vida, às decisões tomadas e às estratégias seguidas pelos indivíduos, apontando, portanto, para dimensões associadas à liberdade). Os processos de produção e reprodução de tais condições também são complexos e multifacetados, embora com certeza

\footnotetext{
${ }^{1}$ Para a análise do acesso mediado por ajuda social no caso de São Paulo ver Marques (2010).
} 
ultrapassem processos e elementos propriamente econômicos, como considerado por uma parte expressiva dos debates, em especial no Brasil.

Seguindo Esping-Andersen (2000) e Mustered, Murie e Kesteloot (2006), consideramos que o bem-estar pode ser provido simultaneamente ao menos por três grandes esferas - Estado, mercados e comunidade/sociabilidade/famílias. Além disso, as condições de acesso a essas esferas podem também variar intensamente entre indivíduos, assim como entre momentos no tempo. Os debates acadêmicos recentes da sociologia relacional, dos estudos urbanos e do neoinstitucionalismo têm nos mostrado que elementos de ao menos três tipos medeiam esses acessos. São eles associados aos padrões de vínculos sociais de que os indivíduos dispõem (suas redes), seus padrões de integração ou de isolamento espacial (a segregação) e elementos de formato e procedimento das políticas públicas, assim como dos próprios mercados econômicos (respectivamente instituições políticas e econômicas ou, mais amplamente, instituições sociais).

Assim, se são centrais para a presença de pobreza o próprio funcionamento das esferas produtoras de bem-estar (o funcionamento do mercado de trabalho, a presença de políticas públicas universalistas, de comunidades e famílias integradoras etc), assim como a existência de atributos individuais que permitam participar dessas fontes de bem-estar (atributos de qualificação profissional para acessar mercados, atributos de cidadania legalizada para acessar políticas, pertencimentos dos indivíduos a coletividades etc), são também essenciais as maneiras pelas quais os indivíduos acessam tais fontes. Dessa forma, acreditamos que perspectivas sobre a pobreza que a consideram meramente a partir da presença de estruturas de oportunidades (Kaztman e Retamoso, 2005) assim como de ativos (Moser, 1998), perdem uma parte significativa dos elementos fundamentais na definição das condições de vida, situados nas estruturas de médio alcance que medeiam os acessos àquelas estruturas de oportunidades. Por essa razão, a consideração simultânea das redes e da segregação é essencial.

Já é relativamente vasta a literatura que conecta pobreza, segregação e redes sociais no âmbito internacional. De uma forma geral, o tema representou um desdobramento da agenda de estudos de segregação urbana, sendo analisado tanto de forma quantitativa como em Briggs (2005), Small (2007) e Ferrand (2002) como qualitativamente (Small, 2009; Mustered, Murie e Kesteloot, 2006; e Blokland e Savage, 2008). Em termos gerais, esses esforços representaram uma forma de precisar e testar vários dos elementos levantados pioneiramente por Wilson (1987) ao conectar o aumento da pobreza com a elevação do isolamento social e espacial nos guetos negros americanos em período recente, face a 
transformações econômicas de maior envergadura. Uma dimensão central nessa discussão é o grau de homofilia presente nos padrões de relações (McPherson et al., 2001), ou o quanto as redes conectam indivíduos com características distintas, ou se simplesmente vinculam pessoas similares socialmente ${ }^{2}$. A utilização das redes permitiria separar analiticamente (e testar separadamente) os efeitos dos dois tipos de isolamento - espacial e relacional.

A presente pesquisa também tem origem nesse tipo de preocupação. Desenvolvemos coletivamente no Centro de Estudos da Metrópole diversos estudos sobre a associação entre pobreza e segregação em registro mais tradicional (Marques e Torres, 2005; CEM, 2004), chegando ao resultado que a segregação tendia a ter um efeito negativo sobre a pobreza, mesmo quando controlado por outras dimensões sociais - indivíduos igualmente pobres mas submetidos diferentemente à segregação tendiam a ter condições sociais distintas, sendo que os mais segregados tinham piores condições sociais. Entretanto, o efeito de isolamento da segregação em si poderia ser combatido, para determinados indivíduos, por suas redes sociais, que poderiam conectá-los 'por sobre o território'. Por essa razão, decidimos desenvolver uma pesquisa que analisasse simultaneamente os efeitos das redes sociais e da segregação sobre a pobreza.

É importante estabelecer como essa pesquisa pensa a causalidade entre redes e atributos sociais. Tanto padrões de relações quanto condições sociais são construídos ao longo das trajetórias de vida dos indivíduos, levando a certas configurações. Embora estudemos tais configurações, associando redes, sociabilidade e atributos sociais, nenhum desses elementos isoladamente é considerado como causa do outro, embora eles se influenciem dinamicamente no tempo. Consequentemente, as distinções e separações desenvolvidas a seguir são meramente analíticas e a causalidade entre eles é considerada como múltipla.

\section{As redes em São Paulo e Salvador}

Antes de tudo precisamos apresentar as características gerais da pesquisa. Em primeiro lugar, é importante estabelecer que pesquisamos redes pessoais, e não redes totais ou de comunidades, ou egonets, por considerar que os padrões de relação mais importantes para especificar as condições dos indivíduos são pessoais, mas não se limitam às vinculações diretas de que um dado ego dispõe. É importante destacar que por redes pessoais não nos referimos apenas às redes

\footnotetext{
${ }^{2}$ A homofilia diz respeito a cada díade em particular e a cada atributo social especificamente. Assim, pode-se perguntar se uma dada relação é homofílica em relação a sexo ou a cor da pele ou a classe social. Mas também podemos calcular a proporção, em uma dada rede, de relações onde os envolvidos nas díades pertencem ao mesmo sexo, tem as mesmas cor da pele ou classe social. Isso permite gerar indicadores do grau de homofilia média nas redes.
} 
egocentradas em torno dos indivíduos, mas às redes totais das sociabilidades cotidianas de tais indivíduos. Esse procedimento permitiu obter redes de tamanho muito variado e com características muito distintas, o que consideramos que é compatível com a heterogeneidade que se pode esperar na sociabilidade dos indivíduos.

O estudo abrangeu duas fases de campo, uma em 2006/2007, na região metropolitana de São Paulo, e outra em 2009 na cidade de Salvador ${ }^{3}$. Em São Paulo, foram realizadas entrevistas com 209 indivíduos em sete localidades escolhidas intencionalmente, levando em consideração estudos anteriores sobre pobreza urbana, de modo a cobrir a variabilidade de situações de segregação e de habitação na cidade. Os locais estudados incluem cortiços do centro de São Paulo, as favelas de Vila Nova Esperança em Taboão da Serra, do Jaguaré e de Paraisópolis em São Paulo e Guinle em Guarulhos ${ }^{4}$, além de conjuntos habitacionais na Cidade Tiradentes e de uma área mista de favela e loteamento irregular no Jardim Ângela. Em Salvador, o trabalho de campo foi conduzido em cinco localidades com base nos mesmos critérios, incluindo cortiços na área do Pelourinho, favelas em duas áreas consolidadas - Curuzu e Amaralina - e em duas regiões periféricas da cidade - o Bairro dos Cabritos nos Alagados e o Bairro da Paz -, totalizando 153 redes pessoais. A escolha dos locais de pesquisa considerou 0 mapeamento dessas áreas como diferentes espaços de pobreza por trabalhos anteriores (Marques e Torres, 2005; CEM, 2004; Carvalho e Pereira, 2006), mas não partiu de uma delimitação prévia dos indivíduos que guiasse a pesquisa por qualquer corte pré-estabelecido de renda, condição de vida ou outros. ${ }^{5}$ Para criar parâmetros para comparar as redes, foram construídas 30 redes de classe média em São Paulo.

\footnotetext{
3 Esses anos são comparáveis, pois o conjunto do período apresentou condições sócio-econômicas similares em termos de emprego, nível de pobreza e estrutura social, considerado o baixo efeito da crise internacional de 2008 sobre a economia brasileira.

${ }^{4}$ Embora haja denominações regionais, denominamos no Brasil cortiços as habitações coletivas nas quais várias famílias habitam um único imóvel, usualmente uma casa grande e mal conservada, com cada família alugando um único cômodo. Todas as famílias repartem o uso do banheiro, da cozinha e da área de serviço, gerando grande precariedade em termos sanitários, muito baixa privacidade e conflitos frequentes. Favelas são assentamentos onde os moradores edificaram (usualmente em autoconstrução) casas em terra ocupada. Loteamentos irregulares são loteamentos que nunca chegaram a ser regularizados, pela presença de alguma irregularidade por parte do empreendedor. A precaridade física pode ser similar à encontrada nas favelas, mas nesse caso os moradores adquiriram a terra, tendo, portanto, situação fundiária muito mais estável.

${ }^{5}$ Evitou-se com esse procedimento cair na discussão das linhas de pobreza ou no debate de como incorporar dimensões não econômicas nos parâmetros definidores das cotas a levantar. Na prática, organizando dessa forma, a separação entre os indivíduos pobres e não pobres no interior desses locais vira um problema empírico, visto que os modelos quantitativos de análise nos informarão sobre os casos discrepantes (outliers) que devem ser removidos da análise, como veremos mais adiante.
} 
Em cada campo a escolha dos entrevistados foi aleatória ao longo de percursos pelos locais estudados, sendo os indivíduos abordados em espaços públicos ou na entrada de suas casas, durante a semana e em fins de semana. A amostra de entrevistados foi controlada por alguns atributos sociais básicos como sexo, idade, status migratório e ocupacional e área de moradia no local estudado. Esse controle objetivou garantir uma proporcionalidade razoável com as características médias da população local e evitar a constituição de vieses. Apesar de não terem sido seguidas técnicas de amostragem estatística aleatória, a comparação das características dos entrevistados com aquelas da população estudada sugere a ausência de viés.

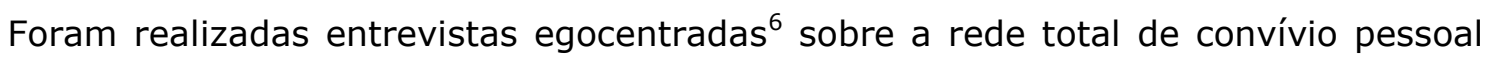
de cada entrevistado, incluindo as várias esferas de sua sociabilidade. As entrevistas completas duraram tipicamente entre cinqüenta minutos e uma hora e envolveram duas partes. Em primeiro lugar era aplicado um questionário semiestruturado referente às características gerais do entrevistado incluindo dados biográficos, composição familiar e do domicílio, status empregatício, trajetória no mercado de trabalho, trajetória migratória, vínculos associativos e práticas de sociabilidade. A segunda parte das entrevistas incluiu a aplicação de uma ferramenta de coleta de dados relacionais com um gerador de nomes e perguntas sobre atributos dos nomes gerados.

Um gerador de nomes é um procedimento adotado para a obtenção de informações relacionais em uma entrevista. Nesse caso o gerador envolveu duas etapas. Inicialmente, realizamos perguntas para obter uma "semente" de nomes a partir das esferas de sociabilidade ${ }^{7}$. As esferas incluíram: familiar, vizinhança, amizade, associativa, diversão/lazer, estudos e profissional e/ou trabalho. Adicionalmente, solicitou-se aos entrevistados pensar em suas relações e citar um conjunto de no máximo cinco nomes para cada esfera de sociabilidade. ${ }^{8}$ Esses nomes constituíram a semente do gerador de nomes. Em seguida, solicitou-se que os entrevistados indicassem até três nomes associados a cada nome da semente, sendo aceitas

\footnotetext{
${ }^{6}$ Entrevistas egocentradas são entrevistas em que se pergunta a um dado indivíduo sobre a sua própria rede. O procedimento não deve ser confundido com redes egocentradas, que são as redes compostas apenas pelos contatos diretos de um dado ego e as conexões entre esses contatos direitos (ou primários, como define o vocabulário técnico).

7 Esferas de sociabilidade são áreas da sociabilidade dos indivíduos definidas de forma cognitiva por eles próprios. Não coincidem com tipos de vínculos ou com atributos dos contatos na rede, mas dizem respeito a 'espaços' da sociabilidade cotidiana. Um entrevistado pode, portanto, incluir um primo (atributo do contato) com quem tem uma relação de amizade (tipo de vínculo) na esfera da vizinhança (esfera), se reconhecer que o contato acontece nesse espaço social.

${ }^{8}$ A limitação de 5 nomes por tipo de esfera, assim como de três contatos por nome incluído na semente (comentado no parágrafo seguinte), foi produto de ajuste no pré-teste da pesquisa. Observamos que a inexistência de limites ou a aceitação de números mais dilatados tendia a concentrar a semente em esferas mais próximas do entrevistado por razões conjunturais do momento da entrevista, resultando em concentração excessiva da rede nessas esferas, posteriormente.
} 
repetições livremente, assim como a indicação de si próprio. Os nomes novos eram acrescentados ao final da lista como a semente de uma nova rodada de entrevista com a mesma pessoa. O procedimento foi repetido três vezes, ou até que não houvesse mais nomes novos. O método nos forneceu um conjunto de díades (pares de nomes ligados por vínculos), indicando a presença de vínculos. Por fim, solicitamos aos entrevistados classificar os nomes citados segundo dois atributos: se o indivíduo é de fora ou de dentro da área estudada e a esfera de sociabilidade a que pertence. Em todos os casos, os valores pré-estabelecidos para os atributos podiam ser alterados na própria entrevista, considerando a alta especificidade das trajetórias, esferas de sociabilidade e das próprias redes.

Em cada uma das cidades, depois de analisar os dados relacionais e construir as redes, retornamos ao campo para realizar entrevistas qualitativas com indivíduos selecionados a partir de uma combinação de características individuais e das redes pessoais. Essas entrevistas exploraram a forma pela qual 38 indivíduos com diferentes tipos de redes as mobilizam para resolução de problemas cotidianos por meio de apoio social, em situações como migração, obtenção de trabalhos, cuidados com crianças e idosos, apoio emocional, etc. A mobilização das redes no caso de São Paulo foi analisada em detalhes por Marques (2010) e não é explorada aqui.

Esses procedimentos levaram à construção de um banco de dados com as informações dos 352 entrevistados e suas redes. A apresentação de algumas informações básicas sobre os entrevistados ajuda a especificar a pesquisa, antes de discutirmos as redes propriamente ditas. Em termos etários, os entrevistados variavam entre 12 e 94, mas com uma grande concentração na idade adulta e médias de idade de 36 anos em São Paulo e 38 em Salvador.

Nos dois casos foram entrevistadas mais mulheres que homens. Em São Paulo as mulheres correspondem a $57 \%$ da amostra, em Salvador elas representam 55\%. Também é semelhante a distribuição no que diz respeito ao estado civil dos entrevistados: em Salvador 50\% dos entrevistados vivem com companheiro, já em São Paulo a proporção é de $56 \%$.

As duas cidades se diferenciam bastante em relação a cor da pele (classificada pelos entrevistadores) e, enquanto em São Paulo 42,4\% dos entrevistados foram classificados como de cor preta, em Salvador a população com essa característica representa $74 \%$ da amostra.

Outra diferença marcante entre as cidades diz respeito à migração. Em São Paulo 70,3\% dos entrevistados eram migrantes; já em Salvador apenas 34\% dos entrevistados não eram nativos de Salvador. Analisando apenas os migrantes nas 
duas cidades, também encontramos algumas diferenças importantes. Em Salvador dentre os migrantes, apenas $11 \%$ está na cidade há menos de 10 anos, já em São Paulo 30\% dos migrantes se encontram nessa mesma condição. Além da baixa migração, Salvador parece ser caracterizado pela pequena mobilidade dos indivíduos em relação a São Paulo. Enquanto em São Paulo, 54\% dos entrevistados moram há mais de 10 anos no mesmo bairro, em Salvador $88 \%$ dos entrevistados possuem essa característica. De fato, o localismo (a proporção dos indivíduos de uma dada rede que habita o mesmo local do entrevistado) é superior em Salvador e uma das principais diferenças entre as redes nas duas cidades (Castello e Marques, 2010).

Em relação à religião observamos que a proporção de evangélicos nas duas cidades é idêntica, $24 \%$ da população é evangélica, embora haja variações com relação às demais religiões. Enquanto em São Paulo 63\% dos entrevistados se diziam católicos e $12 \%$ não tinham religião, em Salvador apenas $45 \%$ dos entrevistados afirmava ser católicos, $22 \%$ dizia não ter religião e $8 \%$ indicava que seguia o candomblé. Ainda em relação às práticas religiosas, os dados indicam maior freqüência a templos na capital baiana. Em Salvador, 45\% entrevistados afirmou freqüentar ao menos 1 vez por semana o culto de sua religião, enquanto em São Paulo apenas 36\% dos entrevistados disseram freqüentar cultos pelo menos 1 vez por semana.

A presença de práticas associativas é baixa nas duas cidades, embora mais elevada em Salvador: em São Paulo $8 \%$ dos entrevistados disseram participar de alguma associação, já em Salvador 16\% dos entrevistados afirmaram a mesma coisa.

Analisando as variáveis relativas à escolaridade e à inserção no mercado de trabalho observamos outras distinções interessantes. Em São Paulo os entrevistados tendiam a ter escolaridade mais baixa - em média 6 anos de estudo, contra média de 7 anos de estudo em Salvador. O mesmo tipo de resultado foi obtido no que diz respeito à população com mais alta escolaridade. Em Salvador, 27\% dos entrevistados concluíram o Ensino Médio e quase 6\% deles chegaram a Universidade, enquanto em São Paulo apenas 16\% dos entrevistados tinham o Ensino Médio completo e menos de 4\% da amostra chegou à Universidade.

Essas posições relativas foram invertidas no caso do rendimento: 19\% em São Paulo e $22 \%$ em Salvador tinham renda familiar per capita inferior a $1 / 4$ do salário mínimo. A média de renda familiar per capita em São Paulo era de 0,82 salários mínimos, enquanto em Salvador a média era de 0,77. 
Quanto aos indivíduos ativos no mercado de trabalho, a maior diferença está na maior proporção de autônomos (bicos) em Salvador $(32,7 \%)$ do que em São Paulo $(20,6 \%)$. Há mais empregados com carteira em São Paulo $(16,3 \%)$, embora a diferença com relação a Salvador não seja tão expressiva $(11,8 \%)$, assim como mais empregados sem carteira em São Paulo $(8,1 \%)$ do que em Salvador $(4,6 \%)$. Considerando-se os não ativos, as diferenças mais expressivas encontram-se na maior presença de donas de casa $(17,7 \%)$ em São Paulo do que em Salvador $(5,2 \%)$, e maior presença de aposentados em Salvador $(11,1 \%)$ contra $2,9 \%$ em São Paulo.

Os níveis de desemprego se assemelham - 11,5\% em São Paulo e 13,1\% em Salvador, embora a precariedade do trabalho fosse maior em Salvador $(64,9 \%)$ do que em São Paulo (57,9\%). O emprego protegido (com carteira, proprietário e negócio familiar) também está mais presente em São Paulo $(40,7 \%)$ do que em Salvador $(31,6 \%)$ - em relação à média de 36,7\%.

A segregação está presente em parte significativa dos domicílios que contemplam a amostra em ambas as cidades, $43 \%$ e $34 \%$ dos indivíduos entrevistados em São Paulo e Salvador, respectivamente, viviam em locais segregados, ou seja, espacialmente distantes/isolados dos centros econômicos das cidades, e relativamente homogêneos internamente.

Foram analisadas 209 redes pessoais em São Paulo e 153 em Salvador, além de 30 redes de classe média de São Paulo, construídas como padrão de comparação. ${ }^{9}$ As principais características são apresentadas na tabela abaixo.

9 A amostra de indivíduos de classe média teve por objetivo apenas construir um parâmetro de comparação para o estudo da heterogeneidade da pobreza. Não houve, portanto, uma preocupação de representar a classe média me termos sócio-ocupacionais ou de rendimento. 0 grupo incluiu profissionais liberais, comerciantes, funcionários públicos e técnicos e funcionários administrativos de entidades privadas. 


\begin{tabular}{|c|c|c|c|c|c|c|}
\hline \multicolumn{2}{|c|}{ Classe e Cidade } & $\begin{array}{l}\text { Total } \\
\text { de nós } \\
\text { na rede }\end{array}$ & $\begin{array}{l}\text { Total de } \\
\text { vínculos }\end{array}$ & $\begin{array}{c}\text { Total de } \\
\text { Esferas } \\
\text { Sociabilidade }\end{array}$ & $\begin{array}{c}\% \text { Vínculos } \\
\text { Sociabilida } \\
\text { de } \\
\text { Primária }\end{array}$ & $\begin{array}{c}\text { \% Vínculos } \\
\text { Sociabilidad } \\
\text { e } \\
\text { Institucional }\end{array}$ \\
\hline \multirow{3}{*}{$\begin{array}{l}\text { Pobres - } \\
\text { São Paulo }\end{array}$} & Média & 52,53 & 53,48 & 3,84 & 77,17 & 22,83 \\
\hline & $\mathrm{N}$ & 209 & 209 & 209 & 209 & 209 \\
\hline & $\begin{array}{l}\text { Desvio } \\
\text { Padrão }\end{array}$ & 29,56 & 36,99 & 1,18 & 19,91 & 19,91 \\
\hline \multirow{3}{*}{$\begin{array}{l}\text { Pobres - } \\
\text { Salvador }\end{array}$} & Média & 40,74 & 74,30 & 3,47 & 79,31 & 17,12 \\
\hline & $\mathrm{N}$ & 153 & 153 & 153 & 153 & 153 \\
\hline & $\begin{array}{l}\text { Desvio } \\
\text { Padrão }\end{array}$ & 26,81 & 53,46 & 1,04 & 15,32 & 15,42 \\
\hline \multirow{3}{*}{$\begin{array}{l}\text { Classe } \\
\text { Média }\end{array}$} & Média & 93,0 & 91,55 & 5,50 & 54,58 & 45,42 \\
\hline & $\mathrm{N}$ & 30 & 30 & 30 & 30 & 30 \\
\hline & $\begin{array}{l}\text { Desvio } \\
\text { Padrão }\end{array}$ & 52 & 55,46 & 2,60 & 21,33 & 21,33 \\
\hline \multirow{3}{*}{ Total } & Média & 51,05 & 64,65 & 3,82 & 76,27 & 22,34 \\
\hline & $\mathrm{N}$ & 391 & 391 & 391 & 391 & 391 \\
\hline & $\begin{array}{l}\text { Desvio } \\
\text { Padrão }\end{array}$ & 33,52 & 47,19 & 1,39 & 19,40 & 19,72 \\
\hline
\end{tabular}

Tabela 1: Características gerais das redes pessoas por cidade de classe social. Fonte: Entrevistas e trabalho de campo.

Em ambas as cidades, as redes analisadas apresentaram tamanhos $\mathrm{e}$ complexidades muito variados, embora essas variações tenham sido similares entre cidades. Em Salvador, em média, as redes tinham 41 nós - variando de 8 a 185 nós - e 74 vínculos, variando de 10 a 387. Em São Paulo, nossos entrevistados apresentaram redes que contêm em média 53 nós, variando de 4 a 179 vínculos. É interessante observar que enquanto o número médio de nós se apresentava levemente maior em São Paulo, em Salvador as redes se destacavam por ter um número médio maior de vínculos. Por outro lado, para termos um parâmetro de comparação, vale reportar que as redes de classe média em São Paulo apresentaram 92 nós e 183 vínculos, em média. Isso sugere que as variações das redes de pobres entre São Paulo e Salvador eram relativamente pequenas e 
tendiam em ambos os casos a ser substancialmente menores do que redes de classe média.

Considerando as esferas de sociabilidade, as redes em Salvador tinham em média 3,5 esferas, variando de 2 a 8 esferas, enquanto em São Paulo a média era de 3,8 esferas, variando de 1 a 7. Esferas de sociabilidade são espaços cognitivamente reconhecidos pelos entrevistados como representando onde ocorre sua sociabilidade. Essa classificação não diz respeito aos tipos de vínculo, como parentesco, por exemplo (dado não coletado sistematicamente pela pesquisa), nem a atributos dos nós, como ser primo ou irmão, novamente para exemplificar. Consequentemente, um dado entrevistado pode afirmar que mantém relações com um primo (que tem atributos de parente) através de uma relação de amizade (que é um tipo de vínculo) no interior da esfera da vizinhança, se assim informar. E com relação às esferas de sociabilidade, novamente as redes da classe média apresentaram características muito distintas das redes de indivíduos em situação de pobreza, alcançando 5,5 esferas diferentes, em média. Portanto, novamente as redes dos pobres tendem a variar pouco entre si entre cidades, embora distem bastante das de classe média.

Talvez a mais importante diferença entre as redes das duas cidades diga respeito ao localismo. Em Salvador encontramos redes proporcionalmente mais locais que em São Paulo - 63,5\% na capital baiana contra 60,5\% em São Paulo. A diferença novamente não parece ser muito elevada se considerarmos que o localismo médio entre a classe média era de 18,0\%. Mas uma análise detalhada do fenômeno (Castello e Marques, 2010) indicou redes sistematicamente mais locais em Salvador, em todas as esferas de sociabilidade, mas mais intensamente nas esferas de sociabilidade potencialmente menos homofílicas em termos amplos socialmente - igreja trabalho e associações. Assim, o mais alto localismo de Salvador se associa a maior homofilia potencial, com efeitos sobre a circulação de informações e oportunidades nas duas cidades. ${ }^{10}$

Portanto, as redes de São Paulo e de Salvador não são muito diferentes, ${ }^{11}$ embora seja muito diversas das de indivíduos da classe média. Esse resultado repete o já encontrado em São Paulo, permitindo sustentar que as redes de indivíduos em situação de pobreza tendem a ser menores, em média, menos diversificadas em

10 No caso dessa pesquisa, entendemos homofilia de forma ampla, no sentido de homofilia social, compreendida conceitualmente como a presença de características similares nos indivíduos envolvidos em relações.

${ }^{11}$ Foram calculados diversos outros indicadores, não discutidos aqui por razões de espaço. Em Salvador a densidade média das redes era de 0,14 ; o diâmetro médio 5,5; grau médio 12,14; coeficiente de clusterização médio 0,519 . Em São Paulo observamos que a densidade média das redes era de 0,$10 ; 0$ diâmetro médio 6,2; grau médio 8,2 e coeficiente de clusterização médio 0,46. Dentre a classe média foi encontrado diâmetro médio 7,4; grau médio 6,00 e coeficiente de clusterização médio 0,560. 
termos de sociabilidade e mais locais do que as redes de classe média. Isso reforça resultados anteriores de Fischer and Shavit (1995), Grosseti (2007) e Lonkila (2010) que sugerem que as redes tendem a variar menos entre sociedades e contextos culturas distintos (ao menos as de apoio pessoal, estudadas por tais autores) do que entre grupos sociais dentro de uma mesma sociedade.

Entretanto, independentemente de suas características médias, as redes tendem a variar consideravelmente dentro de cada grupo - entre os pobres, bem como na classe média. Isso sugeriu que para explorarmos as redes seria preciso analisar a sua heterogeneidade. Isso foi realizado através da utilização de duas análises de cluster. A primeira envolveu o agrupamento dos casos considerando 16 medidas das redes ${ }^{12}$, gerando tipos de redes, enquanto o segundo agrupou os casos em termos da similaridade da distribuição dos nós por esfera de sociabilidade, resultando em diferentes perfis de sociabilidade por esfera. No caso da primeira tipologia encontramos 5 tipos de redes variando das maiores até as menores, sendo que as de tamanho médio apresentavam a menor presença de localismo. 0 Gráfico a seguir resume a informação. Os tipos de redes podem ser ordenados pelos números de nós, embora essa ordenação não dê conta da variação de todas as demais medidas, como o grau de localismo (proporção de vínculos internos), como se pode ver no gráfico.

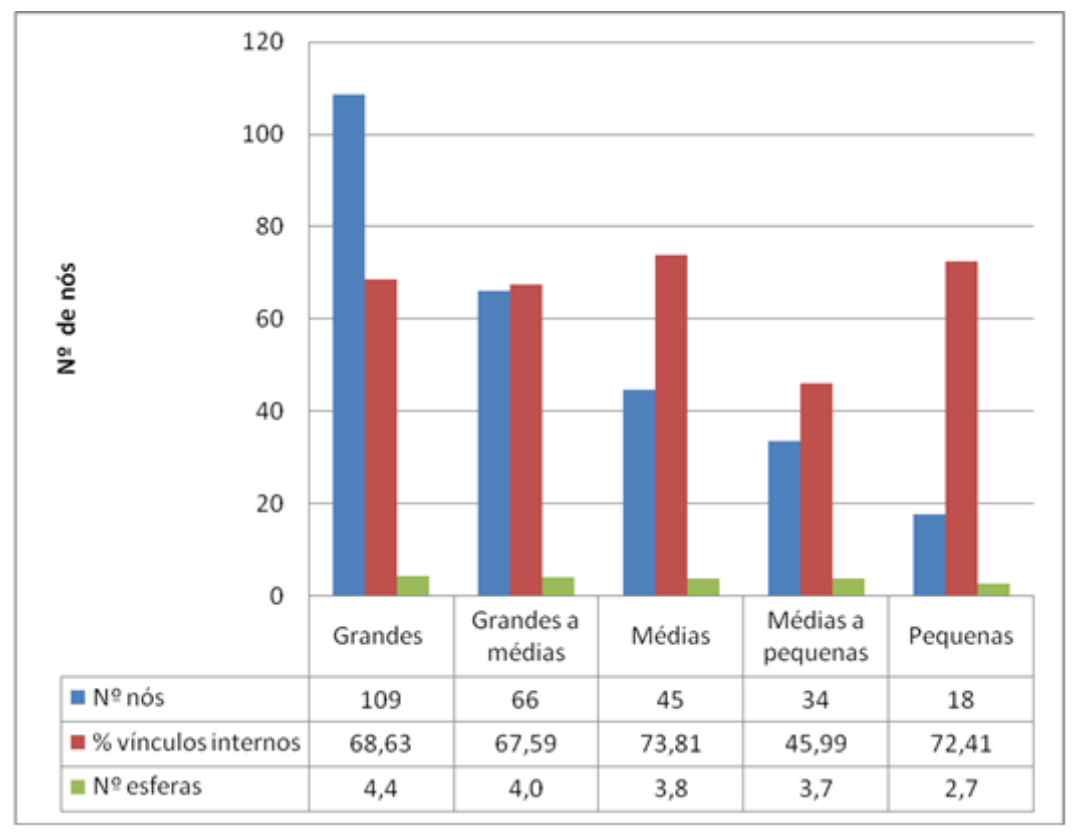

Gráfico 1: Tamanho, localismo e esferas de sociabilidade por tipo de rede. Fonte: Elaboração própria baseada na coleta de dados empíricos

12 Utilizando as seguintes medidas: número de nós, número de vínculos, diâmetro, grau médio, centralização, coeficiente de clusterização, E-I índices, n-clans, intermediação, informação, buracos estruturais, número de contextos e número de esferas. 
Por outro lado, a segunda tipologia indicou a existência de seis tipos diferentes de redes considerando a presença proporcional de cada uma das esferas principais de sociabilidade no total de contatos presentes em cada rede. A Tabela a seguir apresenta a informação. Na tabela podemos observar a existência dos 6 tipos de sociabilidade nas colunas, cada qual com um perfil distinto de sociabilidade considerando a concentração de contatos em cada uma das esferas (apresentados na linhas). Por exemplo, o tipo de sociabilidade concentrada na igreja apresenta $33.3 \%$ dos vínculos na família e $25.3 \%$ na vizinhança (o que não especifica essa sociabilidade, considerando as presenças relativas médias destas esferas), mas apresenta $25,0 \%$ em igrejas, o que é muito superior à média dos entrevistados. Como se pode ver, os tipos de sociabilidade apresentaram concentração nas esferas da família, da vizinhança, dos amigos, da igreja, do trabalho e de associações, respectivamente.

\begin{tabular}{|c|c|c|c|c|c|c|c|}
\hline \multirow[b]{2}{*}{ Esferas } & \multicolumn{6}{|c|}{ Tipo de Sociabilidade } & \multirow[b]{2}{*}{ Total } \\
\hline & Família & Vizinhança & Amizade & Igreja & Trabalho & Associação & \\
\hline Família & 64.07 & 28.75 & 37.41 & 33.34 & 31.37 & 34.47 & 40.57 \\
\hline Vizinhança & 20.68 & 57.08 & 23.96 & 25.32 & 26.41 & 24.80 & 31.61 \\
\hline Amizade & & & 26.22 & 1.84 & 1.65 & & 5.89 \\
\hline Trabalho & & & & 6.16 & 29.05 & & 8.05 \\
\hline Lazer & & & & & & & 1.88 \\
\hline Igreja & & & & 25.02 & & & 4.56 \\
\hline Associação & & & & & & 19.01 & 1.40 \\
\hline Estudos & & & & & & & 3.34 \\
\hline Outros & & & & & & & 1.21 \\
\hline $\mathrm{N}$ de casos & 94 & 86 & 57 & 48 & 55 & 22 & 362 \\
\hline
\end{tabular}

Tabela 2: Tipos de Sociabilidade de acordo com Esferas de Sociabilidade (\%). Fonte: Elaboração própria baseada na coleta de dados empíricos

Nota: Porcentagens abaixo de $6 \%$ foram omitidas. Células escuras possuem porcentagens acima da média e células cinza claro representam concentrações significativas, apesar de estar abaixo da média.

Se encontramos 5 tipos de redes e 6 tipos de sociabilidade, poderíamos ter 30 situações potencialmente. Entretanto, o cruzamento das tipologias e a análise do significado das situações com relação à homofilia potencial, ao localismo e à variabilidade da sociabilidade indicou apenas das quatro combinações potencialmente existentes respondiam por $92,4 \%$ do total das redes pessoais analisadas. São elas: 
a) Sociabilidade Primária em Redes Pequenas ${ }^{13}$

b) Sociabilidade Primária em Redes Médias

c) Sociabilidade Primária em Redes Grandes

d) Sociabilidade Organizacional em Redes Médias ${ }^{14}$

Os quatro tipos são igualmente presentes em São Paulo e Salvador, mas como vermos a seguir estão associadas de forma bastante distintas com as condições sociais dos indivíduos.

\section{Redes e acesso a mercados}

Completada a análise descritiva básica das redes, já estamos em condição de investigar as associações entre atributos dos indivíduos, variáveis relacionais e de sociabilidade, e condições sociais usualmente relacionadas à pobreza. No caso, testamos a obtenção de trabalho, de trabalho com algum grau de proteção, a presença de situações de vulnerabilidade social (medida de forma composta considerando estrutura familiar, renda, trabalho e habitação) e o montante de rendimentos das pessoas em situação de pobreza.

A análise dessas associações foi realizada utilizando diferentes técnicas quantitativas considerando as variáveis em jogo. Para analisar os determinantes de ter emprego, ter emprego protegido, e estar sujeito a acúmulo de precariedades, optamos por utilizar um método exploratório conhecido como árvore de Chaid (Chisquared automatic Interaction Detection). Esse método testa as relações entre uma variável dependente, necessariamente categórica, e outras preditoras, a partir da estatística qui-quadrado. Para investigar os condicionantes das redes e de atributos dos indivíduos sobre a renda (no caso renda domiciliar mensal per capita), utilizamos regressão múltipla. Os resultados mostram que os padrões de sociabilidade e relacional dos indivíduos têm destaque na explicação dessas dimensões, juntamente com as variáveis tradicionais, tais como nível educacional e o tamanho do domicílio. A situação de segregação, já intensamente associada pela literatura às condições de pobreza, como já destacado, também se mostra significativa, embora aparecendo com efeitos diferentes em São Paulo e em Salvador, causados provavelmente pelas diferentes estruturas urbanas.

\footnotetext{
${ }^{13}$ Chamamos de sociabilidade primária a sociabilidade baseada em relações sociais primárias, presentes nas esferas da família, da amizade e da vizinhança. É razoável imaginar que esse tipo de sociabilidade é potencialmente mais homofílica.

14 Chamamos de sociabilidade organizacional a sociabilidade baseada em relações construídas e mantidas no interior de organizações. É razoável imaginar que esse tipo de sociabilidade é potencialmente menos homofílica.
} 


\section{Trabalho}

Em primeiro lugar analisamos os condicionantes da condição de trabalho, talvez a mais geral a mediar o acesso dos indivíduos a mercados. Consideramos como tendo 'trabalho' os indivíduos que afirmaram ter trabalho regular (formal ou não, doméstico ou não) além dos que trabalham em negócios familiares e os pequenos proprietários. Consideramos como 'sem trabalho' os indivíduos desempregados, além dos que afirmaram viver de bicos, dada a estrutura muito precária da maior parte das atividades indicadas nessa categoria. ${ }^{15}$ Segundo essa definição, tinham trabalho 122 pessoas $(33,7 \%)$, contra 137 casos que não tinham $(37,8 \%)$. Para outros 103 casos $(28,0 \%)$ - estudantes, pensionistas e aposentados e donas de casa - essa distinção não fazia sentido sendo, portanto, retirados da análise.

Tendo então 'ter trabalho' como variável dependente, a análise seguiu a aplicação da técnica de Chaid aos casos, considerando variáveis independentes similares às utilizadas para as redes dos pobres em São Paulo contidas em Marques (2010) e indicadoras de dimensões sociais relacionais, sócio-econômicas, etárias, migratórias e espaciais. ${ }^{16}$

A cada nível da árvore, o procedimento compara a variável dependente com cada uma das independentes isoladamente, escolhendo a que apresenta associação com mais alta significância (considerando a estatística qui-quadrado). O conjunto dos casos é então dividido segundo os valores dessa variável independente e cada subgrupo novamente comparado com cada uma das independentes resultantes, escolhendo- se a que apresentar maior associação. O procedimento é repetido até que não haja mais associações significativas ou que os subgrupos não apresentem casos suficientes para a análise prosseguir. O modelo resultante é o apresentado abaixo. ${ }^{17}$

\footnotetext{
${ }^{15}$ Apenas para dar idéia dessa precariedade, listamos algumas atividades nessa categoria - carregador ocasional de caminhão, ajudante de florista ocasional, montador de andaimes ocasional, vendedor ambulante de balas, entre outros.

${ }^{16}$ Relacionais: número de nós da rede individual, número de vínculos, grau médio, tamanho eficiente da rede egocentrada, centralização, coeficiente de clusterização, proporção de pessoas externas à área, número total de esferas, variáveis dicotômicas ("dummy") referentes aos tipos de redes com cinco grupos, variáveis dicotômicas referentes aos tipos de sociabilidade e de rede, assim como às suas combinações; Sócio-econômicas: sexo do indivíduo, anos de estudo, renda familiar per capita, freqüenta igreja ou templo mais do que quinzenalmente; participa de alguma associação. Por motivos óbvios as variáveis associadas a emprego não foram incluídas no modelo, visto que fazem parte da definição da variável dependente; Etárias: idade do indivíduo, idoso (60 anos ou mais), jovem (idade menor ou igual do que 21 anos); Migratórias: proporção de conterrâneos maior ou igual a 21\%. Migratórias: proporção de conterrâneos maior ou igual a $21 \%$. Espacial: segregado.

17 Vale reportar que quando os casos de classe média são incluídos nas análises, a primeira variável em todas as árvores que se seguem é a escolaridade, indicando que entre grupos sociais, o seu poder de discriminação social é muito significativo. Apenas entre os pobres, entretanto, tanto a sua variação, quanto a sua associação com outros atributos se enfraquece, sendo suplantada por dimensões associadas às sociabilidade e às redes.
} 


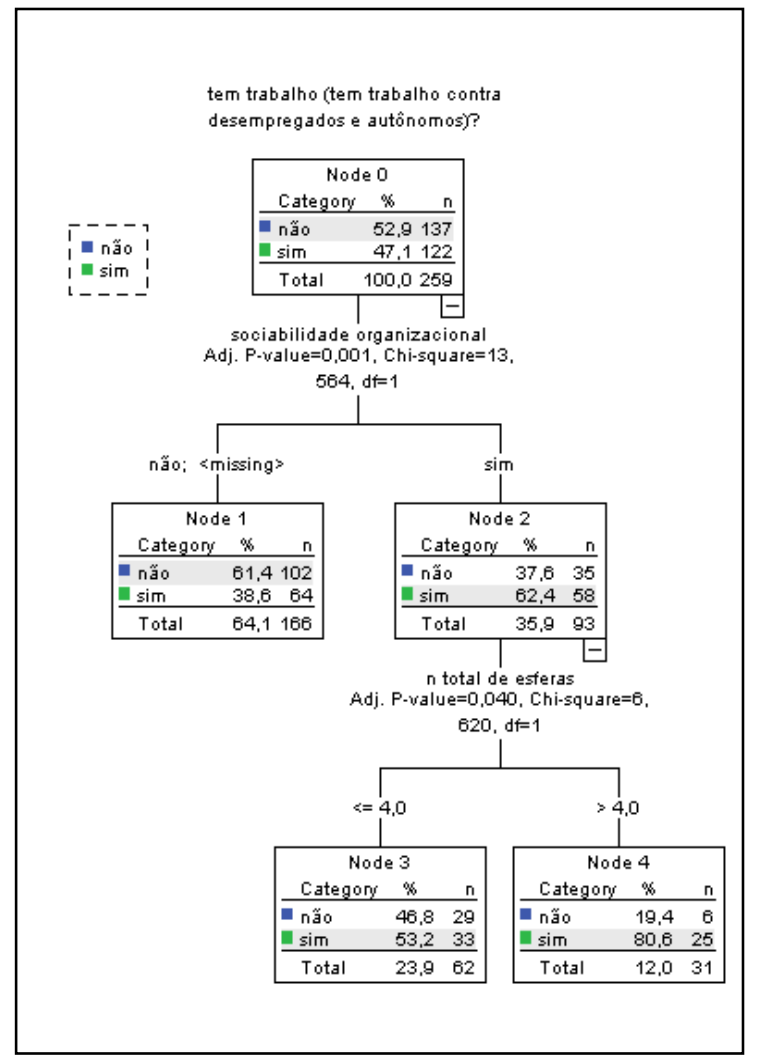

Figura 1 - Análise de CHAID de Trabalho, São Paulo e Salvador Fonte: Análise dos autores a partir de dados de campo.

Do conjunto de indivíduos incluídos nesse modelo, 47,1\% afirmavam ter trabalho. Nesse modelo, a variável que mais se associava à variação dessa condição era ter sociabilidade construída no interior de organizações, que como já vimos está ligada a menor presença potencial de homofilia. Entre os indivíduos com esse tipo de sociabilidade, a presença de trabalho era de fato substancialmente maior - $62,4 \%$ contra $38,6 \%$ em média de quem tinha sociabilidade concentrada em esferas primárias.

Entretanto, o segundo nível do modelo nos informa que dentre aqueles com sociabilidade organizacional, tendem a ter trabalho mais comumente as pessoas que tem sociabilidade variada, com mais de 4 esferas diferentes. Dentre esses, a condição de trabalho alcança $80,6 \%$, enquanto entre os que têm até 4 esferas $53,2 \%$ tem trabalho. O modelo classificou corretamente $61,8 \%$ dos casos, o que pode ser considerado como um ajuste satisfatório.

A diferença entre as duas situações extremas, portanto, é de 42,0\% (entre $80,6 \%$ e 38,6\%), mostrando que o modelo realmente discrimina situações sociais distintas. Análises anteriores realizadas somente com base nas redes pessoais de São Paulo apresentaram resultados similares, embora centradas apenas na 
sociabilidade organizacional ${ }^{18}$. Portanto, dentre todo o conjunto de variáveis analisadas, os indivíduos que mais frequentemente têm emprego tendem a ter sociabilidade e redes potencialmente menos homofílicas, além de sociabilidade variada.

\section{Trabalho Protegido}

Mas os indivíduos podem ter empregos, mas com graus de proteção muito diferentes, o que aponta para horizontes muito distintos de previsibilidade e, consequentemente, de vulnerabilidade social potencial. Assim, um segundo modelo testa os principais condicionantes das situações de trabalho protegido. Consideramos como 'trabalho protegido' a presença de trabalhos com registro profissional em carteira, domésticos ou não, trabalhar em negócios familiares ou ser proprietário. Considerando o funcionamento do mercado de trabalho para os tipos de ocupação típicas dos entrevistados, entretanto, também incluímos como 'trabalho protegido' trabalho sem registro em carteira no mesmo local de trabalho há mais de um ano, doméstico ou não. Por outro lado, não tinham trabalho protegido os desempregados, que viviam de bicos e trabalhadores sem registro no trabalho atual há menos de um ano. A condição de trabalho protegido envolvia 95 pessoas (26,2\%), contra 164 casos que não tinham (45,3\%). Para outros 103 casos $(28,0 \%)$ - estudantes, pensionistas, donas de casa e aposentados - essa distinção não fazia sentido sendo, portanto, retirados da análise.

Também nesse caso foi realizada uma análise de Chaid com variáveis relacionais, sócio-econômicas, migratórias, etárias e espaciais, com o resultado a seguir. ${ }^{19}$

\footnotetext{
${ }^{18}$ No caso de São Paulo a variável de maior poder de discriminação também era a presença ou não de sociabilidade organizacional, mas o modelo não chegava a abrir um segundo nível. A diferença pode se dever ao menor número de casos analisados em Marques (2010), que impediu o método de estabelecer um segundo nível de discriminação.

${ }^{19}$ Relacionais: número de nós da rede individual, número de vínculos, grau médio, tamanho eficiente da rede egocentrada, centralização, coeficiente de clusterização, proporção de pessoas externas à área, número total de esferas, variáveis dicotômicas ("dummy") referentes aos tipos de redes com cinco grupos, variáveis dicotômicas referentes aos tipos de sociabilidade e de rede, assim como às suas combinações; Sócio-econômicas: sexo do indivíduo, anos de estudo, renda familiar per capita, freqüenta igreja ou templo mais do que quinzenalmente; participa de alguma associação. Por motivos óbvios as variáveis associadas a emprego não foram incluídas no modelo, visto que fazem parte da definição da variável dependente; Etárias: idade do indivíduo, idoso (60 anos ou mais), jovem (idade menor ou igual do que 21 anos); Migratórias: proporção de conterrâneos maior ou igual a $21 \%$. Espacial: segregado
} 


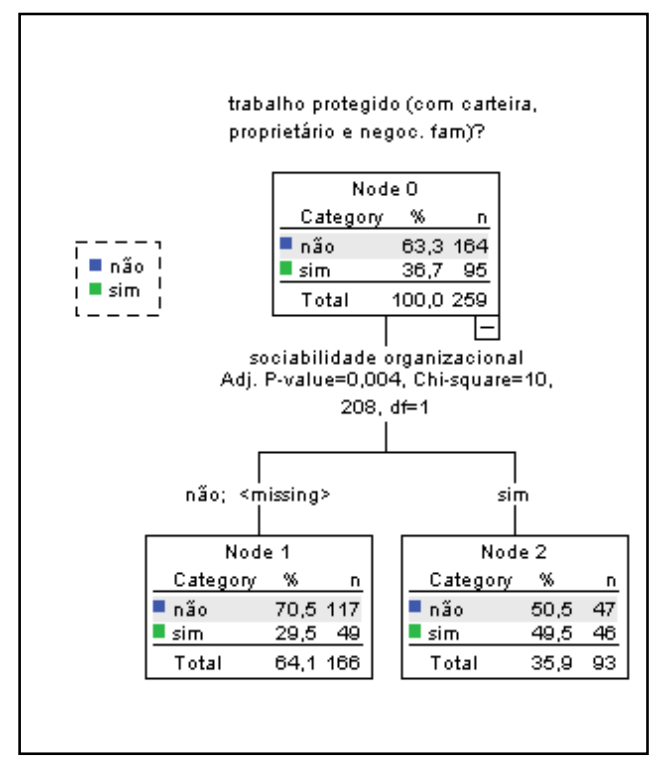

Figura 2: Análise de CHAID de Trabalho protegido, São Paulo e Salvador.

Fonte: Análise dos autores a partir de dados de campo.

Como podemos ver no modelo, apenas $36,7 \%$ das pessoas incluídas na análise têm trabalho protegido. A exemplo da análise anterior, a árvore nos indica que a variável que mais discrimina essa situação é ter ou não sociabilidade construída em ambientes organizacionais, onde a presença de homofilia é potencialmente menor. Dentre os que têm esse tipo de sociabilidade $49,5 \%$ dos indivíduos tem trabalho com algum grau de proteção, contra apenas $29,5 \%$ dos indivíduos com outros tipos de sociabilidade. O modelo classificou corretamente $63,3 \%$ dos casos.

O modelo confirma, portanto, que tipos de sociabilidade discriminam fortemente as situações de trabalho dos indivíduos, tanto a sua presença, quanto o grau de proteção. Novamente as melhores situações sociais estão associadas a menores níveis potenciais de homofilia em sentido amplo, resultado que repete o encontrado em São Paulo.

\section{Precariedade}

Embora todos os entrevistados sejam pobres, há importantes diferenças nos seus níveis de pobreza, como já vimos. Assim, decidimos testar os condicionantes da presença de situações de elevada precariedade social, que separa os indivíduos mais precários entre os pobres. Para tal utilizamos como situação a ser explicada um indicador sintético de precariedade composto por dimensões familiares, habitacionais de renda e de trabalho. ${ }^{20}$ Consideramos como 'precários' os indivíduos 
com duas ou mais dentre as quatro condições, sendo todos os demais indivíduos considerados como não precários. Apresentavam precariedade segundo essa definição $24 \%$ dos entrevistados, sendo não precários os restantes $76 \%$

Também nesse caso foi realizada uma análise de Chaid com variáveis relacionais, sócio-econômicas, migratórias, etárias e espaciais.

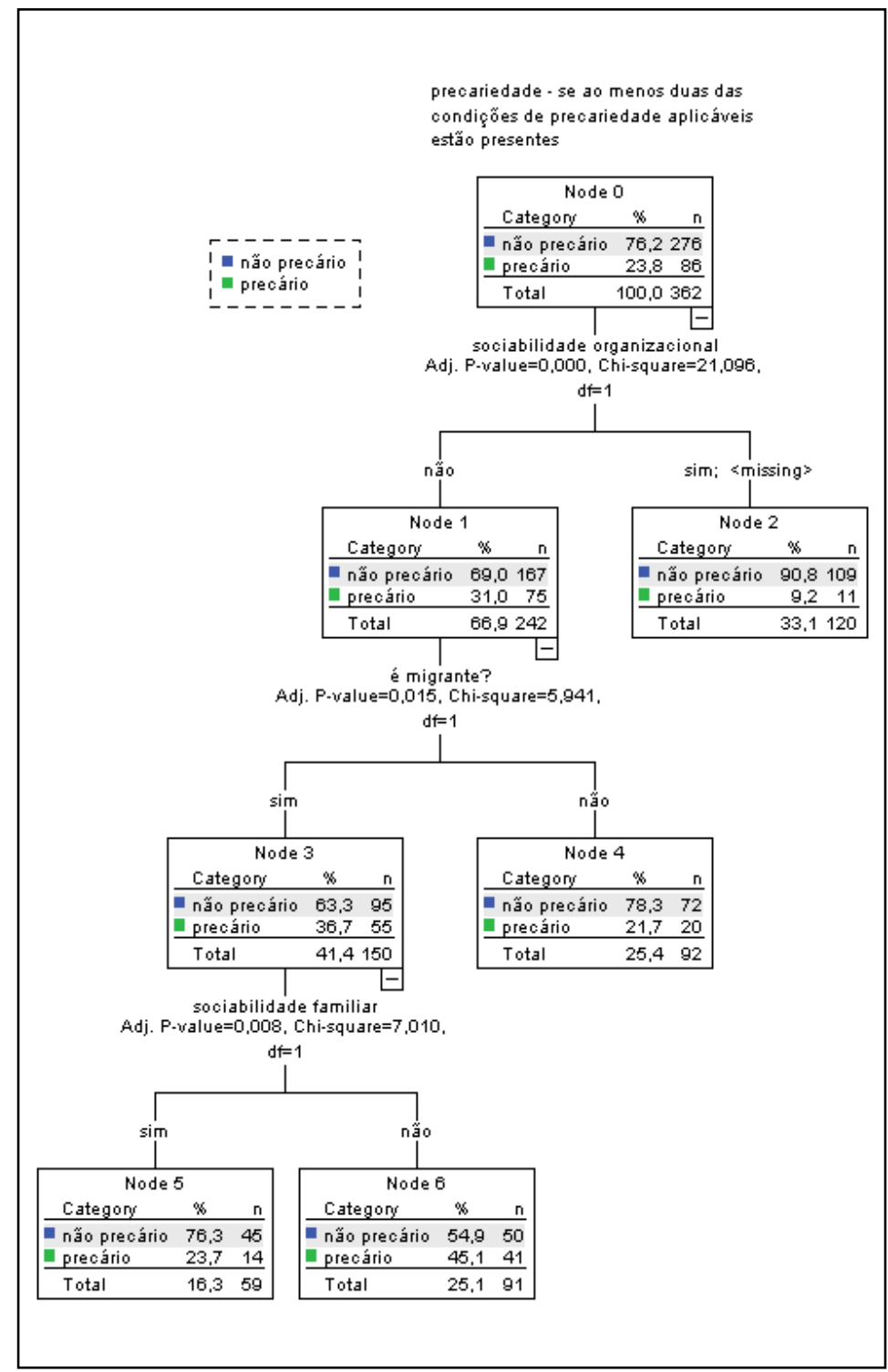

Figura 3: Análise de CHAID de Precariedade, São Paulo e Salvador.

Fonte: Análise dos autores a partir de dados de campo. ocasionais ou trabalho em vínculo informal sem continuidade no tempo. 
O modelo indica que o indicador composto de precariedade está associado mais uma vez à sociabilidade centrada em ambientes organizacionais. ${ }^{21}$ Dentre aqueles que têm esse tipo de sociabilidade, a precariedade envolve apenas 9,2\% das pessoas, enquanto entre os indivíduos com todos os demais perfis de sociabilidade a precariedade atinge $31,0 \%$, em média. Por outro lado, o segundo nível da árvore nos indica que dentre aqueles que não têm sociabilidade organizacional, a migração é um segundo fator predominante. Para os migrantes a presença de precariedade é de $36,7 \%$, enquanto para os não migrantes alcança apenas $21,7 \%$. O terceiro nível especifica a situação dos migrantes que não tem sociabilidade organizacional. Dentre eles, os que contam com sociabilidade centrada na família tem situação de precariedade menos frequente - 23,7\% - contra 45,1 dos que tem sociabilidades de outros tipos (na vizinhança e entre amigos, dado o primeiro nível da árvore). 0 modelo classificou $76,2 \%$ dos casos corretamente.

Novamente, portanto, tipos de sociabilidade e de redes se mostram centrais, embora nesse caso associados ao status migratório. A interpretação do resultado nos parece clara - o elemento mais fortemente associado à ausência de precariedade entre os pobres é a presença de sociabilidades organizacionais. $\mathrm{Na}$ ausência dessas, dimensões associadas à maior ou menor integração social no local de moradia podem mitigar a situação. Os migrantes, por contarem com menos recursos de vários tipos, tendem a apresentar situação mais precária do que os não migrantes. Mas mesmo entre os migrantes, os que contam com um contexto familiar forte em termos relacionais, podem reduzir as chances de cair em situações precárias. A importância da sociabilidade familiar, entretanto, apenas especifica a situação de quem já não teve acesso às formas de integração anteriores.

A diferença entre as situações polares - 35,9 (de 45,1 a 9,2\%) -, indica que também nesse caso as redes e sociabilidades discriminam substancialmente as situações sociais. O modelo encontrado apenas para os casos de São Paulo é praticamente idêntico. $^{22}$

\footnotetext{
${ }^{21}$ Relacionais: número de nós da rede individual, número de vínculos, grau médio, tamanho eficiente da rede egocentrada, centralização, coeficiente de clusterização, proporção de pessoas externas à área, número total de esferas, variáveis dicotômicas ("dummy") referentes aos tipos de redes com cinco grupos, variáveis dicotômicas ("dummy") referentes aos tipos de sociabilidade e de rede, assim como às suas combinações; Sócio-econômicas: sexo do indivíduo, anos de estudo, freqüenta igreja ou templo mais do que quinzenalmente; participa de alguma associação; Etárias: idade do indivíduo, idoso (60 anos ou mais), jovem (idade menor ou igual do que 21 anos); Por motivos óbvios as variáveis associadas a renda e emprego não foram incluídas no modelo, visto que fazem parte da definição da variável dependente. A variável 'segregado' também foi retirada, pois se encontra correlacionada por definição com os cortiços e, consequentemente, com a definição de precariedade habitacional.

${ }^{22}$ No caso da precariedade a diferença com o caso de São Paulo diz respeito à ordem explicativa da migração e da sociabilidade familiar - em Marques (2010) sociabilidade familiar apareceu no segundo nível e migração no terceiro. Os grupos finais, portanto, são levemente diferentes e a pior situação em São Paulo diz respeito à ausência de sociabilidade organizacional também de sociabilidade familiar, sem indicação relativa à migração, enquanto aqui diz respeito a migrantes com ausência de sociabilidade
} 


\section{Rendimentos}

Essa seção completa a análise da influência das redes sobre o acesso a bens e serviços obtidos através de mercados, investigando os principais condicionantes dos rendimentos dos indivíduos em situação de pobreza. Como já vimos padrões relacionais são centrais para a especificação das situações dos indivíduos com relação a trabalho, trabalho com alguma proteção e vulnerabilidade social. Mas de que forma eles impactam os rendimentos monetários, ou mesmo se o fazem quando se consideram conjuntamente outras variáveis convencionalmente associadas à pobreza, como a escolaridade.

Para responder a tal pergunta foram utilizados modelos de regressão múltipla linear, tendo como variável dependente os rendimentos domiciliares per capita dos indivíduos. Considerando a diferença entre as datas das coletas de dados nas duas cidades, as rendas domiciliares foram divididas pelos valores dos salários mínimos vigentes em cada momento. Dadas premissas de linearidade, o modelo que melhor se ajustou tem como variável dependente a raiz quadrada na renda domiciliar mensal per capita dos indivíduos da amostra. Foram testados modelos separados para cada cidade e um único para o conjunto das observações, sendo esse último formato escolhido. A tabela a seguir resume os principais parâmetros do modelo.

\begin{tabular}{|l|l|l|l|l|l|l|l|}
\hline & \multicolumn{2}{|c|}{ Coeficientes } & \multicolumn{3}{c|}{$\begin{array}{c}\text { Coeficientes } \\
\text { padronizados }\end{array}$} & \multicolumn{2}{c|}{$\begin{array}{c}\text { Intervalo de confiança } \\
(95 \%)\end{array}$} \\
\hline & B & $\begin{array}{l}\text { Erro } \\
\text { padrão }\end{array}$ & Beta & $\mathrm{t}$ & Sig (t) & $\begin{array}{l}\text { Limite } \\
\text { inferior }\end{array}$ & $\begin{array}{l}\text { Limite } \\
\text { superior }\end{array}$ \\
\hline Constante &, 792 &, 057 & & $\begin{array}{l}13,94 \\
3\end{array}$ &, 000 &, 681 &, 904 \\
\hline Anos de estudo &, 012 &, 004 &, 144 & 3,349 &, 001 &, 005 &, 019 \\
\hline No pessoas no domićílio &,- 062 &, 006 &,- 399 & $-9,614$ &, 000 &,- 075 &,- 049 \\
\hline $\begin{array}{l}\text { Redes organizacionais e } \\
\text { médias }\end{array}$ &, 129 &, 033 &, 173 & 3,945 &, 000 &, 065 &, 193 \\
\hline $\begin{array}{l}\text { Interação No de nós e } \\
\text { renda estável }\end{array}$ &, 004 &, 001 &, 302 & 7,150 &, 000 &, 003 &, 005 \\
\hline No de esferas &, 026 &, 013 &, 090 & 1,969 &, 050 &, 000 &, 052 \\
\hline Segregado &,- 064 &, 028 &,- 095 & $-2,290$ &, 023 &,- 118 &,- 009 \\
\hline
\end{tabular}

Tabela 3: Coeficientes da Regressão linear múltipla da Raiz quadrada da renda domiciliar mensal per capita. Fonte: Dados coletados pelos autores em campo.

Nota: $\mathrm{R}^{2}$ ajustado de 0,414 , com 353 casos. 9 casos foram excluídos do modelo sete outliers $(215,153,159,287,355,307,352)$, e outros 2 casos apresentavam perda de informação. 
Como podemos ver, seis variáveis apresentaram significância na explicação da variação da renda domiciliar per capita. O modelo tem um $\mathrm{R}^{2}$ ajustado de 0,414 , o que pode ser considerado um bom resultado para esse tipo de análise. Foram incluídos 353 casos, deixando de fora dois casos com perda de informação e sete outros que apresentavam comportamento discrepante (3 de São Paulo e 4 de Salvador). Não por acaso, dentre esses se incluem dois proprietários, a filha de um proprietário (que trabalha em seu negócio), além de um fotógrafo. Em geral os efeitos podem ser sumarizados como se segue.

Em primeiro lugar, a escolaridade afeta positivamente a renda. Esse resultado, de resto já esperado, indica que quanto maior o número de anos de estudos de um dado indivíduo, maior tende a ser a sua renda, mesmo em face às outras variáveis. A próxima variável também se inclui entre as tradicionalmente consideradas em estudos do tema. Trata-se do tamanho do domicílio, que afeta negativamente os rendimentos. Resultado também esperado indica que à medida em que cresce o número de moradores do domicílio, a renda tende a cair. O efeito poderia ser interpretado como meramente numérico, mas a variável dependente em questão já foi dividida pelo número de indivíduos (já que diz respeito a um per capita do domićlio), sugerindo que a dependência criada por moradores adicionais apresenta um efeito quadrático sobre os rendimentos, mesmo que nesses já estejam incluídos os rendimentos de todo o domicílio.

As próximas variáveis apontam para dimensões pouco ou nada exploradas pela literatura sobre o tema, ao menos em nível nacional. Em terceiro lugar, ter um tipo específico de rede - de tamanho médio, pouco local e com sociabilidade construída em ambientes potencialmente menos homofílicos - tem efeito positivo sobre a renda. Esse resultado confirma os obtidos nas análises anteriores e demonstra a forte associação entre padrões de relações de baixa homofilia e melhores condições de vida.

Além disso, para quem tem emprego estável, o tamanho da rede afeta positivamente a renda. Para quem tem trabalho precário ou não tem trabalho, não há efeito do tamanho da rede. O efeito medido pelo modelo provavelmente se associa ao impacto de longo prazo que os padrões de relações conseguem obter para os indivíduos que contam com estabilidade nas atividades de trabalho e, portanto, tem trajetórias de maior previsibilidade e constância.

A quarta variável nos indica que a variabilidade da sociabilidade também impacta positivamente a renda e, quanto maior o número de esferas, mais elevados tendem a ser os rendimentos. A quinta e última variável indica que viver em locais segregados afeta negativamente a renda dos indivíduos, o que é coerente com as 
discussões sobre pobreza e segregação. No caso de São Paulo analisado em Marques (2010), a variabilidade da sociabilidade aparecia associada às situações de segregação, indicando um efeito da variabilidade apenas entre os indivíduos segregados. Para o conjunto dos casos das duas cidades, efeitos dissociados são indicados pelo modelo, com a variabilidade da sociabilidade afetando positivamente e a segregação negativamente os rendimentos. Essa diferença pode se dever ao menor número de casos, mas também a uma maior importância da variabilidade da sociabilidade para a conexão dos segregados em São Paulo, dados a maior escala desta cidade e o maior localismo de Salvador.

Portanto, os resultados confirmam as análises de Chaid realizadas anteriormente, e além de variáveis tradicionalmente relacionadas às condições de vida dos indivíduos como escolaridade, inserção no mercado de trabalho e tamanho do domicílio, os tipos de redes pessoais e de sociabilidade dos indivíduos mais pobres, assim como as situações de segregação social no espaço, impactam as condições de vida dos indivíduos, quando medidas pelo acesso a bens e serviços obtidos em mercados.

\section{Conclusão}

Nessa conclusão retomamos os principais resultados apresentados ao longo do artigo. Pudemos ver que as redes de indivíduos em situação de pobreza não variam muito entre São Paulo e Salvador, apesar das grandes diferenças entre as cidades em termos urbanos, de estrutura social, de mercado de trabalho e de padrões de pobreza. A dimensão que apresentou maiores diferenças disse respeito ao localismo, sendo os padrões de relação em Salvador mais locais do que em São Paulo, o que foi explicado pela maior consolidação dos bairros na capital baiana, tendo como consequência que a maior parte dos moradores habita no mesmo local de maneira estável há muito mais tempo do que seus congêneres em São Paulo.

Por outro lado, encontramos grandes diferenças entre as redes de indivíduos pobres e de classe média, sendo as dos primeiros menores, menos variadas em termos de sociabilidade, mais locais e mais centradas em esferas potencialmente homofílicas. Apesar disso, as redes também variaram intensamente entre os pobres, sugerindo a existência de padrões heterogêneos no interior dos grupos sociais. A construção de tipologias comprovou esse achado, mostrando que se podemos encontrar entre os pobres redes locais e potencialmente homofílicas (tanto grandes quanto pequenas), também se fazem presentes redes pouco locais, potencialmente menos homofílicas e de tamanho médio. 
As análises quantitativas posteriores mostraram que os tipos de rede e de sociabilidade estão fortemente associados à possibilidade de se ter trabalho, em especial trabalho com proteção, assim como estar em situação de vulnerabilidade social. Em todos esses casos, sociabilidades construídas de forma intensa em ambientes organizacionais, assim como sociabilidades mais variadas, se associam a melhores condições sociais. No caso da precariedade, quando os indivíduos não contam com tais padrões de sociabilidade, a presença de sociabilidade na família e o fato de ser não migrante podem atenuar a presença dessas situações.

Por fim, pudemos constatar que juntamente com variáveis tradicionais como a escolaridade e o número de pessoas no domicílio, variáveis relacionadas às redes dos indivíduos ajudam a explicar os rendimentos domiciliares per capita. Novamente a presença de redes construídas em ambientes organizacionais e sociabilidades mais variadas se mostram associadas a melhores situações sociais, nesse caso rendas mais elevadas. Além disso, para indivíduos que contam com trabalho estável a renda tende a aumentar com o tamanho da rede. Confirmando resultados anteriores da literatura, se os indivíduos se encontram segregados sua renda tende a ser menor, mesmo em face aos efeitos já observados. É importante notar que esse último efeito já aparecia para o caso de São Paulo, mas podia ser contrabalançado naquela cidade pela presença de sociabilidade variada para os indivíduos segregados que a conseguissem construir. Considerando as duas cidades conjuntamente, variabilidade da sociabilidade tem um efeito positivo, e segregação tem impacto negativo, mas de forma independente.

Portanto, os padrões de relações dos indivíduos são centrais para a explicação das suas condições sociais. Redes e sociabilidade mais locais, potencialmente mais homofílicas, e menos variadas, tendem a se associar sistematicamente com piores condições sociais. Dentre as várias consequências desses resultados, vale terminar esse artigo destacando o caráter de circularidade presente na associação entre esses elementos, contribuindo potencialmente para a perpetuação da pobreza de forma persistente.

\section{Bibliografia}

Bidart, C. e Lavenu, D. (2005). "Evolution of personal networks and life events". Social Networks, 27 (4): 359-376.

Blokland, T. e Savage, M. (2008). Social capital and Networked urbanism. London: Basil Blackwell.

Briggs, X. (2005). "Social capital and segregation in the United States". In: Varady, D. Desegregating the city. Albany, Suny Press. 
Carvalho, I. e Pereira, G. (org) (2006). Como anda Salvador. Salvador, Edufba.

Castello, G. e Marques, E. (2010). Pobreza e Localismo: Comparações entre São Paulo e Salvador. Artigo apresentado no XXXV Encontro da Anpocs, Caxambu.

CEM. (2004). Mapa da Vulnerabilidade Social da População da Cidade de São Paulo. São Paulo, CEM/Cebrap; SAS/PMSP.

Degenne, A. (2009). "Tipos de interacciones, formas de confiança y relaciones". Redes - Revista hispana para el análisis de redes sociales, Vol. 16 (3): 63-91.

Esping-Andersen, G. (2000). Fundamentos sociales de las economías postindustriales. Barcelona, Ariel.

Ferrand, A. (2002). "Las comunidades locales como estructuras meso". Revista Hispana para el Análisis de Redes Sociales, vol. 3(4), set-nov.

Fischer, C. e Shavit, Y. (1995). National differences in network density: Israel and the United States. Social Networks, (17(2), 129-145.

Grossetti, M. (2007). Are French networks different? Social Networks, 29(3), 391404.

Hedstrom, P.; Sandell, R. e Stern, C. (2000). "Meso-level networks and the diffusion of social movements". American Journal of Sociology, 106(1): 145-172.

Heinz, J.; Laumann, E.; Nelson, R. e Salisbury, R. (1997). Hollow core: private interests in national policy making. Cambridge, Harvard University Press.

Jariego, I. (2002). "Tipos de redes personales de los inmigrantes y adaptación psicológica". Redes: Revista Hispana para el Análisis de Redes Sociales, vol. (1(1), jan.

Kadushin, C. (1995). "Friendship Among the French Financial Elite". American Sociological Review, 60: 202-221.

Kaztman, R. e Retamoso, A. (2005). "Spatial segregation, employment and poverty in Montevideo". Cepal Review, 85: (125-142.

Knoke, D.; Pappi, F.; Broadbent, J. e Tsujinaka, Y. (1996). Comparing policy networks: labor politics in the U.S., Germany, and Japan. Cambridge, Cambridge University Press.

Lonkila, M. (2010). "The importance of work-related social ties in post-soviet Russia: the role of co-workers in the personal networks in St. Petersburg and Helsinki". Connections, vol. 30(1), 46-56. 
Marques, E. (2010). Redes sociais, segregação e pobreza. São Paulo: Ed. Unesp/CEM.

Marques, E. e Torres, H. (2005). São Paulo: segregação, pobreza urbana e desigualdade social. São Paulo, Ed. Senac.

McPherson, M.; Smith-Lovin, L. e Cook, J. (2001). "Birds of a feather: homophily in social networks". Annual Review of Sociology, 27: 415-444.

Moser, C. (1998). "The asset vulnerability framework: reassessing Urban Poverty Reduction Strategies". World Development, Vol. 26(1): 1-19.

Mustered, S.; Murie, A. e Kestellot, C. (2006). Neighborhoods of poverty: urban social exclusion and integration in Europe. London: Palgrave Ed.

Mische, A. (2008). Partisan publics. Princeton: Princeton University Press

Small, M. (2007). "Racial Differences in Networks: Do Neighborhood Conditions Matter?" Social Science Quarterly, Vol 88 (2).

Small, M. (2009) Unanticipated gains: origins of network inequality in everyday life. Oxford: Oxford University Press.

Wilson, W. (1987). The truly disadvantage: the inner city, the underclass and public policy. University Chicago Press. 